\title{
A NATUREZA CONTRADITÓRIA DA EDUCAÇÃO ESCOLAR: TENSÃO HISTÓRICA ENTRE HUMANIZAÇÃO E ALIENAÇÃO
}

\author{
LA NATURALEZA CONTRADICTORIA DE LA EDUCACIÓN ESCOLAR: TENSIÓN \\ HISTÓRICA ENTRE HUMANIZACIÓN Y ALIENACIÓN
}

\author{
THE CONTRADITORY NATURE OF SCHOOL EDUCATION: HISTORICAL \\ TENSION BETWEEN HUMANIZATION AND ALIENATION
}

\author{
Ana Carolina Galvão MARSIGLIA ${ }^{1}$ \\ Lígia Márcia MARTINS ${ }^{2}$
}

\begin{abstract}
RESUMO: O artigo objetiva promover reflexões acerca das teorias pedagógicas em seu caráter histórico e contraditório, analisando as implicações desse processo para a educação contemporânea. Identifica que o projeto neoliberal, tendo em vista a reestruturação produtiva, exige um "novo" tipo de trabalhador: flexível, adaptável, com capacidade empreendedora e competências socioemocionais, etc. Isso confere determinada valoração ao conhecimento para o capital, qual seja, manter e ampliar a própria existência do modo de produção capitalista. Desse modo, subjuga a formação do trabalhador a uma semiformação, sob marcos de precarização, exploração e alienação. Sendo assim, observamos que a educação escolar não foi, até hoje, uma arma para a classe trabalhadora, tendo em vista sua emancipação. Constatamos, pois, a contradição entre a possibilidade humanizadora, aqui concebida como desenvolvimento máximo da consciência dos indivíduos e a alienação, representativa dos processos que apartam os sujeitos das conquistas do gênero humano e, dentre elas, o acesso aos conhecimentos aptos ao desvelamento do real. Destarte, para que a educação escolar opere a serviço da humanização e contra a alienação há que se afirmá-la pela qualidade dos conhecimentos que veicula e pela defesa do ato de ensiná-los.
\end{abstract}

PALAVRAS-CHAVE: Educação escolar. Historicidade. Humanização. Alienação.

RESUMEN: El artículo objetiva promover reflexiones acerca de las teorías pedagógicas en su carácter histórico y contradictorio, analizando las implicaciones de ese proceso para la educación contemporánea. Identifica que el proyecto neoliberal, con vista a la reestructuración productiva, exige un "nuevo" tipo de trabajador: flexible, adaptable, con capacidad emprendedora y competencias socioemocionales, etc. Esto confiere cierta valoración al conocimiento para el capital, qual sea, mantener y ampliar la propia

${ }^{1}$ Universidade Federal do Espírito Santo (UFES), Vitória - ES - Brasil. Doutora em Educação Escolar. Professora do Centro de Educação da Líder do grupo de pesquisa Pedagogia histórico-crítica e educação escolar, membro do Núcleo de Educação Infantil (NEDI-UFES), do Grupo de pesquisa Estudos Marxistas em Educação. ORCID: <http://orcid.org/0000-0001-8451-8269>. E-mail: galvao.marsiglia@gmail.com

${ }^{2}$ Universidade Estadual Paulista (UNESP), Araraquara - SP - Brasil. Professora do Programa de PósGraduação em Educação Escolar. Livre Docente em Psicologia da Educação. Vice-líder do Grupo de pesquisa Estudos Marxistas em Educação. ORCID: <http://orcid.org/0000-0002-4293-9580>. E-mail: ligiamar@fc.unesp.br 
existencia del modo de producción capitalista. De este modo, subyuga la formación del trabajador a una semiformación, bajo marcos de precarización, explotación y alienación. Siendo así, observamos que la educación escolar no ha sido, hasta hoy, una arma para la clase obrera, teniendo en vista su emancipación. Constatamos, pues, la contradicción entre la posibilidad humanizadora, aquí concebida como desarrollo máximo de la conciencia de los individuos y la alienación, representativa de los procesos que apartan a los sujetos de las conquistas del género humano y, entre ellas, el acceso a los conocimientos aptos al desvelamiento del real. Para que la educación escolar opere al servicio de la humanización y contra la alienación hay que afirmarla por la calidad de los conocimientos que transmite y por la defensa del acto de enseñarlos.

PALABRAS CLAVE: Educación escolar. Historicidad. Humanización. Alienación.

ABSTRACT: The article aims to promote reflections about pedagogical theories in their historical and contradictory character, analyzing the implications of this process for contemporary education. It identifies that the neoliberal project, in view of this restructuring, requires a "new" type of worker: Flexible, adaptable, with entrepreneurial capacity, etc. This attributes certain value to knowledge for capital, that is, to maintain and expand the very existence of the capitalist mode of production. In this way, it subjugates the formation of the worker to the semiformation, under conditions of precarization, exploitation and alienation. In this sense, we observe that school education has not, to this day, been a weapon for the working class that could be used for its emancipation. We thus find the contradiction between the humanizing possibility, here identified with the maximum development of the consciousness of individuals and alienation, which is a representative of the processes that separate the subjects of the human-generic conquests, and among them, the access to the knowledge able to unveil reality. Thus, for school education to operate at the service of humanization and against alienation, one must affirm it by the quality of the knowledge it conveys and by the defense of the act of teaching them.

KEYWORDS: School education. Historicity. Humanization. Alienation.

\section{Breve introdução às teorias pedagógicas em seu caráter histórico e contraditório.}

A educação é um fenômeno próprio dos seres humanos. Isso porque tomamos como premissa que a atividade vital humana é o trabalho, que se explica pela relação de transformação da natureza pelos seres humanos. Assim, o trabalho, em sua acepção ontológica, forma o ser humano, por meio das mediações instituídas a cada novo ser da espécie por aqueles que já constituem o conjunto da humanidade. Ora, humanizar o ser humano é, pois, um processo educativo (SAVIANI, 2007b). Entretanto, se a origem da educação coincide com a própria origem humana, a existência histórica de proprietários e 
não-proprietários cria uma cisão, desde a Antiguidade, entre educação e trabalho. Como explica Saviani (2007b, p. 155):

\begin{abstract}
A partir do escravismo antigo passaremos a ter duas modalidades distintas e separadas de educação: uma para a classe proprietária, identificada como a educação dos homens livres, e outra para a classe não-proprietária, identificada como a educação dos escravos e serviçais. A primeira, centrada nas atividades intelectuais, na arte da palavra e nos exercícios físicos de caráter lúdico ou militar. E a segunda, assimilada ao próprio processo de trabalho. A primeira modalidade de educação deu origem à escola.
\end{abstract}

A origem da educação escolar expressa, portanto, a contradição entre a humanização necessária de todos os indivíduos e a possibilidade de acesso aos conteúdos requeridos a ela, fundamentalmente voltados aos membros de uma só classe, aquela dos homens livres. Vale ressaltar, como alerta Saviani (2008b), que a pedagogia da essência entende que os seres humanos são essencialmente iguais. Porém, na Antiguidade Grega, por exemplo, “[...] o escravo não era considerado ser humano, consequentemente, a essência humana só era realizada nos homens livres" (idem, p. 31). Assim, na Grécia, o caráter classista da educação aparecia por meio de uma educação integral que, no entanto, “[...] ensinava uns poucos a governar" (GADOTTI, 2002, p. 30).

O caso das elites romanas não é diferente, pois os plebeus (homens livres que não tinham linhagem nobre e não possuíam direitos políticos) precisaram lutar pelo direito de uma educação aristocrática - o que só é pautado a partir do surgimento dos "plebeus enriquecidos" pelo comércio, que fazem surgir essa nova classe, não mais estabelecida em função da linhagem nobre de sangue, mas sim, pela riqueza. De todo modo, permanece a incumbência aos escravos (sem instrução), da garantia da produção material dos nobres, conservando, pois, também em Roma, a restrição do acesso à educação escolar.

$\mathrm{Na}$ Idade Média, com uma educação controlada pela Igreja Católica, as escolas paroquiais objetivavam a doutrinação dos camponeses para que se mantivessem sob controle, deixando para a nobreza e o clero a formação em escolas monásticas e imperiais (GADOTTI, 2002). No que se refere à pedagogia da essência, a Idade Média apresenta "[...] uma inovação, que diz respeito [...] à articulação da essência humana com a criação divina” (SAVIANI, 2008b, p. 31), justificando assim a diferença entre senhores e servos. É do período medieval também a criação das primeiras universidades, que permitiram “[...] à 
burguesia emergente [...] participar de muitas vantagens que até então só pertenciam ao clero e à nobreza" (GADOTTI, 2002, p. 56).

É justamente a ruptura com o modo de produção feudal que coloca a burguesia como classe em ascensão, revolucionária, que defende a igualdade entre os indivíduos, fazendo-a reivindicar a substituição de "[...] uma sociedade com base num suposto direito natural por uma sociedade contratual" (SAVIANI, 2008b, p. 32). Inaugura-se a época moderna e a transição para o modo de produção capitalista. A passagem de Saviani (2008b, p. 32-33) explica com clareza os interesses burgueses que levam a essa nova base das relações de produção e suas implicações para a educação escolar.

\begin{abstract}
Os homens são essencialmente livres; essa liberdade funda-se na igualdade natural, ou melhor, essencial dos homens, e se eles são livres, então podem dispor de sua liberdade, e na relação com os outros homens, mediante contrato, fazer ou não concessões. É sobre essa base da sociedade contratual que as relações de produção vão se alterar: do trabalhador servo, vinculado à terra, para o trabalhador não mais vinculado à terra, mas livre para vender a sua força de trabalho e ele a vende mediante contrato. Então, quem possui os meios de produção é livre para aceitar ou não a oferta de mão-de-obra, e vice-versa, quem possui a força de trabalho é livre para vendê-la ou não, para vendê-la a este ou aquele, para vender a quem quiser. Esse é o fundamento jurídico da sociedade burguesa. Fundamento [...] formalista, de uma igualdade formal. No entanto, é sobre essa base de igualdade que vai se estruturar a pedagogia da essência e, assim que a burguesia se torna a classe dominante, ela vai, a partir de meados do século XIX, estruturar os sistemas nacionais de ensino e vai advogar a escolarização para todos. Escolarizar todos os homens era condição para converter os servos em cidadãos, era condição para que esses cidadãos participassem do processo político, e, participando do processo político, eles consolidariam a ordem democrática, democracia burguesa, é obvio, mas o papel político da escola estava aí muito claro. A escola era proposta como condição para a consolidação da ordem democrática.
\end{abstract}

Ocorre, no entanto, que consolidada como classe dominante, a burguesia vê seus interesses ameaçados, o que a leva a defender, em termos educativos, a pedagogia da existência, afirmando que os seres humanos são essencialmente diferentes, com capacidades, motivações e interesses próprios a cada um. Com esse princípio, em nome do suposto respeito às diferenças, legitima-se a desigualdade de acesso ao patrimônio humano-genérico, bem como a dominação e os privilégios. Como sublinha Gadotti (2002, p. 93) 
A nova classe mostrou [...] ao apagar das "luzes" da Revolução de 1789, que não estava de todo em seu projeto a igualdade dos homens na sociedade e na educação. Uns acabaram recebendo mais educação que outros. Aos trabalhadores, diria ADAM SMITH (1723-1790), economista político burguês, será preciso ministrar educação apenas em conta-gotas. A educação popular deveria fazer com que os pobres aceitassem de bom grado a pobreza, como afirmara o próprio Pestalozzi. Esse grande educador acabava de enunciar o princípio fundamental de educação burguesa que ministrou uma educação distinta para cada classe: à classe dirigente a instrução para governar e à classe trabalhadora a educação para o trabalho.

Mais uma vez, evidencia-se a contradição entre trabalho (em seu sentido ontológico) e educação, posto que à classe subalterna não estaria garantido o acesso aos bens materiais e imateriais da produção humana, submetendo-a à exploração.

A pedagogia da existência, que começa a tomar forma na Idade Moderna, com Rousseau (1712-1778), Pestalozzi (1746-1827) e Froebel (1782-1852), consolida o movimento escolanovista no século XIX, tendo como grande referência o norte-americano John Dewey (1859-1952), “[...] o primeiro a formular o novo ideal pedagógico, afirmando que o ensino deveria dar-se pela ação [...] e não pela instrução [...]. A educação preconizada por Dewey era essencialmente pragmática, instrumentalista. Buscava a convivência democrática sem, porém, pôr em questão a sociedade de classes" (GADOTTI, 2002, p. 143). Vale salientar que o suíço Jean Piaget (1896-1980), influência destacada na educação no século XX, foi grande leitor das obras de Dewey, fazendo referência ao filósofo pragmatista em suas obras.

No final da primeira metade do século XX, diante da ineficiência da Escola Nova para resolver o problema da marginalidade ${ }^{3}$ (SAVIANI, 2008b), uma nova teoria educacional, visando atender os interesses do modo de produção capitalista, se articula: trata-se da pedagogia tecnicista, que chega ao Brasil em meados da década de 1960. Nela, professores e alunos são deslocados ao plano secundário, assumindo papel de executores do processo planejado, controlado e coordenado por "[...] especialistas supostamente habilitados, neutros, objetivos e imparciais" (idem, p. 11). Em termos de marginalidade, esta teoria pedagógica entenderá como marginalizado, o incompetente. Assim,

\footnotetext{
${ }^{3}$ Segundo Saviani (2008b), o problema da marginalidade, na Escola Tradicional, se expressava por meio dos indivíduos ignorantes, que precisavam ser ilustrados. Já na Escola Nova, era marginalizado o diferente, que deveria ser aceito em suas capacidades e potencialidades. Se resolvida a questão da marginalidade, a escola estaria garantindo a educação escolar adequada aos indivíduos. No entanto, no caso da Escola Tradicional, ela não se universalizou e a Escola Nova só agravou essa marginalização, ao oferecer ensino precarizado à classe trabalhadora pautado na defesa das particularidades de cada indivíduo.
} 
considerando que a centralidade desta pedagogia está na organização dos meios para operacionalização do trabalho pedagógico, era preciso mecanizar o processo de modo a minimizar as interferências que viessem a prejudicar o resultado esperado, qual seja, “[...] formar indivíduos eficientes, isto é, aptos a dar sua parcela de contribuição para o aumento da produtividade da sociedade" (idem, ibidem). E assim, novamente, a educação escolar não se prestou a garantir as condições de humanização necessárias ao pleno desenvolvimento dos indivíduos, fragmentando a formação humana e colaborando para a permanência das condições de alienação.

Pelo exposto, visamos destacar a relação de condicionabilidade recíproca entre a educação escolar, caracterizada pelas teorias pedagógicas que lhe conferem sustentação, e os ordenamentos sociais requeridos pelos modos de produção, relação esta que, historicamente, coloca a escola no cerne das contradições sociais. Na sequência, dedicamos atenção especial à contemporaneidade, com destaque às teorias pedagógicas hegemônicas, tendo em vista apontar como e em que medida acompanhamos o acirramento do traço contraditório em tela.

\section{Teorias pedagógicas "pós": o acirramento da contradição entre humanização e alienação.}

A década de 1980 foi marcada pelo processo de mundialização da economia, que encontra no neoliberalismo a retórica que legitima a reordenação do Estado em função do atendimento das necessidades do capital.

Nesse contexto, se inicia no Brasil um clima de reconstrução da ordem democrática com intensa ascensão de movimentos sociais e organização de segmentos da assim chamada "sociedade civil", para garantia do exercício da cidadania. Entretanto, democracia e cidadania, palavras tão fortes e intensamente utilizadas nesse período com conotação crítica, não explicitaram de fato um projeto histórico de transformação social. Segundo Pereira (2006, p. 25), “[...] a ferocidade do período da ditadura militar impediu a adoção de uma linguagem clara em relação aos vários projetos históricos [...]", ocasionando ambiguidade na compreensão do que seria "transformação da sociedade" - o fim da ditadura ou a própria sociedade capitalista?

Para Saviani (2010), o processo de abertura democrática que se deu nesse período, foi marcado pela conciliação, resultando na garantia da continuidade da ordem econômica, 
visto que não representou para a classe trabalhadora um processo de ruptura que verdadeiramente significasse a libertação do proletariado da exploração capitalista.

Pedagogicamente, a década de 1980 abriu as portas para o construtivismo, amplamente adotado como referência central no campo educacional, no interior do qual as aprendizagens expressam conhecimentos relativizados, tanto porque estão vinculadas à vida cotidiana dos indivíduos (as culturas locais se sobrepõem à cultura universal) como porque todo o conteúdo apreendido depende de um ponto de vista, construído por cada sujeito.

Não podemos desconsiderar que foi também na década de 1980 que se deu fôlego as pedagogias contra-hegemônicas, mas, no contexto da década de 1990, marcado pela hegemonia do ideário neoliberal e pós-moderno, verifica-se que, diante das frustradas tentativas de implantação de políticas educacionais "de esquerda" na década de 1980, refluíram as adesões dos educadores aos movimentos progressistas (SAVIANI, 2010).

A situação posta na década de 1990, em continuidade ao que anteriormente havia se iniciado, é a da reestruturação produtiva do capital, com vistas à flexibilização do trabalho, terceirização, imposição de normas de qualidade e produtividade, diminuição do emprego, mudanças nas relações de trabalho (subemprego, trabalho doméstico, etc.), redução do poder dos sindicatos e perda de direitos trabalhistas (LIMA, 1998).

O projeto neoliberal, tendo em vista essa reestruturação, exige um "novo" tipo de trabalhador: flexível, adaptável, com capacidade empreendedora, etc. Isso nos permite indagar, como Carvalho (2010), qual é o verdadeiro valor do conhecimento para o capitalismo? Segundo o autor, para o capital só tem valor “[...] o conhecimento que possibilita a ampliação e a manutenção da sua existência. O conhecimento, seja da natureza, seja das relações sociais, que cada vez mais amplie a extração do trabalho excedente, que aumente a mais-valia sobre o trabalhador" (CARVALHO, 2010, p. 23-24).

Esse quadro subjuga a formação do trabalhador à construção de competências, sob marcos de precarização, exploração e alienação, que se traduzem nas teorias pedagógicas que vão dominar a partir de então, pois

[...] apesar de dizerem que a educação não deve ter um caráter estritamente utilitarista, mas também preocupar-se com o ser humano como o "fim último do desenvolvimento", a relação entre empregabilidade, adaptação e flexibilidade surge como a nova articulação entre a educação e o trabalho, e como possibilidade para o 
desenvolvimento "das melhores capacidades dos seres humanos" (SALA, 2009, p. 65-66).

Portanto, foi preciso assegurar ideologicamente um discurso de cidadania, igualdade, garantias sociais, etc., ainda que não se efetivem na socialização da acumulação do capital. Como afirma Carvalho (2010, p. 27), as reformas educacionais da década de 1990, que promoveram menos investimentos e nivelamento por baixo da educação, resultam no "[...] fortalecimento do ensino de conteúdos de civilidade e cidadania para a convivência democrática, o que nada mais é do que a própria ideologia burguesa plasmada numa circunstância concreta das relações sociais".

Em termos das ideias pedagógicas desse período, que se estende até a atualidade (ainda que com atualizações que aprofundam cada vez mais o esvaziamento da educação escolar), conforme Saviani (2010, p. 428)

Não é fácil caracterizar em suas grandes linhas essa nova fase das ideias pedagógicas. Isso porque se trata de um momento marcado por descentramento e desconstrução das ideias anteriores, que lança mão de expressões intercambiáveis e suscetíveis de grande volatilidade. Não há, pois, um núcleo que possa definir positivamente as ideias que passam a circular já nos anos de 1980 e que se tornam hegemônicas na década de 1990. Por isso sua referência se encontra fora delas, mais precisamente nos movimentos que as precederam. Daí que sua denominação tenda a se fazer lançando mão das categorias precedentes às quais se antepõem prefixos do tipo "pós" ou "neo".

Seja em suas expressões de base neoprodutivista, neoescolanovista, neoconstrutivista ou neotecnicista (SAVIANI, 2010), as pedagogias contemporâneas hegemônicas guardam em comum alguns aspectos: 1) a valorização da educação escolar; 2) contudo, esse enaltecimento é restrito a uma forma escolar voltada ao desenvolvimento do trabalhador para a empregabilidade; 3) disso decorre uma preparação "polivalente", permanente e adaptativa ao mercado; 4) logo, a formação do sujeito é pautada com base em suas capacidades, interesses e necessidades, que serão ensinadas por meio do desenvolvimento de competências para determinadas situações; 5) há, pois, um esvaziamento dos conteúdos escolares, que produzem uma formação humana insuficiente; 6) a escola se desresponsabiliza do processo educativo imputando ao próprio indivíduo seu fracasso. Da mesma forma que o Estado se desresponsabiliza pela escola.

Como podemos observar, a educação escolar não foi, até hoje, uma arma para a classe trabalhadora, que pudesse ser utilizada para sua emancipação. Saviani (2008b), ao 
tratar da mudança de interesses da burguesia (de classe revolucionária à classe dominante), assinala que nesse deslocamento, a burguesia não se alinha mais ao desenvolvimento histórico, que caminha em direção à transformação da sociedade. Ao defender sua consolidação no poder, a burguesia "[...] não tem outra saída senão negar a história, passando a reagir contra o movimento da história" (idem, p. 33). Essa negação da história permanece nos interesses atuais, uma vez que a educação escolar continua, a passos largos, perdendo cada vez mais seu caráter humanizador e decisivo para a formação das novas gerações. É nesse sentido que passamos ao último tópico desse estudo, buscando explicitar como o avanço das crises do capital é alimentado pelas formas inferiores de educação e vice-versa.

\section{A perda da dimensão ontológica do trabalho e o empobrecimento subjetivo pela via da educação escolar}

Como ser social, produtor e produto da cultura, os indivíduos se desenvolvem e complexificam, o que lhes dá condições de captar, dominar e transformar a realidade. Quanto mais se complexifica essa relação, mais necessário se torna o desenvolvimento do psiquismo humano, que ao converter os objetos da natureza em conceitos - e realizando esse processo em suas máximas possibilidades, objetiva, em cada indivíduo, aquilo que o conjunto dos seres humanos acumulou historicamente (MARTINS, 2013). Cria-se um universo simbólico (conceitual), que, como tal, pode ou não refletir a realidade objetiva. Sendo assim, cabe à educação escolar colocar-se a serviço do desvelamento da realidade concreta, dado que não se realiza em detrimento da natureza dos conteúdos de ensino.

No entanto, a escola, como parte da engrenagem social capitalista, não vem cumprindo (como demonstrado) seu papel de formação dos indivíduos e colaborado, inversamente, para a desumanização. Vejamos o que escreveu Marx (2010, p. 82) nessa passagem clássica sobre a separação do trabalhador dos produtos do trabalho:

$\mathrm{O}$ trabalho produz maravilhas para os ricos, mas produz privação para o trabalhador. Produz palácios, mas cavernas para o trabalhador. Produz beleza, mas deformação para o trabalhador. Substitui o trabalho por máquinas, mas lança uma parte dos trabalhadores de volta a um trabalho bárbaro e faz da outra parte máquinas. Produz espírito, mas produz imbecilidade, cretinismo para o trabalhador. 
No caso da educação escolar, não é diferente. Apesar de o capitalismo ter o conhecimento como força produtiva e, portanto, não poder desprezar a escolarização da classe trabalhadora, "[...] a sociedade capitalista desenvolveu mecanismos por meio dos quais procurar expropriar o conhecimento dos trabalhadores e sistematizar, elaborar esses conhecimentos, e devolvê-los na forma parcelada" (SAVIANI, 2014, p. 114), ou, como diriam Antunes e Pochmann $(2007)^{4}$, realiza-se uma liofilização ${ }^{5}$ dos conteúdos escolares, transformando-os em algo morto, vazio, insuficiente, pobre. Em outras palavras, o empobrecimento dos indivíduos, com contributo da educação escolar, leva à perda da dimensão civilizatória da sociedade, isto é, à barbárie.

Portanto, educar em tempos de crise social demanda resgatar o caráter humanizador da educação. Assim, não é por acaso que Saviani (2011) afirma que o trabalho (atividade vital humana de transformação da natureza e do ser) da educação (fenômeno próprio aos seres humanos, por meio do qual são transmitidos os conhecimentos das gerações anteriores) é garantir que cada novo ser da espécie humana (indivíduo singular) se aproprie dos conhecimentos já elaborados pelo gênero humano (universal) ao longo de sua história, o que se realiza em particulares condições históricas e sociais. É o que nos explica Martins (2013, p. 10), destacando a importância da qualidade das apropriações que fazemos:

[...] a filosofia marxista evidencia a historicidade do processo de superação do ser hominizado em direção ao ser humanizado, processo que, para se efetivar, demanda a inserção de cada indivíduo particular na história do gênero humano. Porém, para que essa inserção ocorra, não é suficiente nascer e viver em sociedade, não basta o contato imediato com as objetivações humanas. Para que os indivíduos se insiram na história, humanizando-se, eles precisam de educação, da transmissão da cultura material e simbólica por parte de outros indivíduos. No ato educativo, condicionado pelo trabalho social, reside a protoforma do ser social, isto é, de um ser cujo desenvolvimento é condicionado pela qualidade das apropriações que realiza.

Destarte, se a humanização é produto das relações sociais e das aprendizagens delas decorrentes, é preciso analisar em que condições os indivíduos se humanizam (ou se desumanizam). Sabemos que numa sociedade de classes essas condições não estão

${ }^{4}$ Os autores utilizam o termo para tratar da reestruturação produtiva e o enxugamento das empresas. Segundo eles, o resultado desse processo é a "[...] expansão daquilo que Juan Castillo cunhou como liofilização organizacional, um processo no qual substâncias vivas são eliminadas” (ANTUNES; POCHMANN, 2007, p. 198).

${ }^{5}$ Processo químico por meio do qual se desidrata uma substância líquida. 
dispostas da mesma maneira a todos os sujeitos e é justamente por seu alinhamento à perspectiva socialista, que tanto a pedagogia histórico-crítica quanto a psicologia históricocultural vão defender a socialização do conhecimento como função da educação escolar, por meio da qual os indivíduos podem desenvolver a consciência (subjetivação da realidade objetiva) e assim transformar a si e à sociedade. Pode soar romântica essa afirmação; pode inclusive dar margem a equivocadas interpretações de que estaríamos dando à escola o papel estratégico de estopim de um levante revolucionário. Nem uma coisa, nem outra. Somos anuentes com Saviani (2008b), que desde a obra "Escola e Democracia", vem exaustivamente repetindo que a escola não é redentora da humanidade.

Por outro lado, se as transformações sociais necessitam de fortes organismos de base, como associações, sindicatos e partidos, a possibilidade de compreender um novo ordenamento social demanda um alto grau de desenvolvimento da consciência que devemos conquistar para elevar o universo das significações, para além das mais imediatas e aparentes dimensões da realidade (MARTINS, 2013). E essa elevação se dá pela apropriação da cultura em suas formas mais desenvolvidas, cujo acesso sistematizado e intencional se dá por meio da escola.

Ao advogarmos o ensino escolar em suas relações com a formação da consciência não estamos nos referindo, como explica Saviani (2014), à consciência ingênua, impotente, ilusória, mas sim, uma consciência crítica, com clareza dos limites e condicionantes objetivos aos quais estamos submetidos. Em tempos de obscurantismo, retrocessos e fundamentalismos, com frontais, diários e violentos ataques à classe trabalhadora, defender a escola é um ato de resistência e, também, uma forma de se ter a esperança requerida à construção de uma sociedade mais igualitária.

\section{A título de finalização: por uma educação escolar que tenha a humanização como polo prevalente}

Pelo exposto buscamos demonstrar que, tanto quanto quaisquer outros processos educativos, a educação escolar se faz marcada pelas contradições engendradas pela sociedade de classes. Dentre elas, colocamos em foco a contradição entre a possibilidade humanizadora, aqui identificada com o desenvolvimento máximo da consciência dos indivíduos e a alienação, representativa dos processos que apartam os sujeitos das conquistas humano-genéricas e, dentre elas, o acesso aos conhecimentos aptos ao desvelamento do real. 
Tais condições exigem um posicionamento político, a orientar uma escolarização que opere a favor de um polo - humanização, e contra outro - alienação; e é com vista a este ideal que advogamos um ensino voltado à formação da consciência dos indivíduos. Todavia, para tal empreendimento, precisamos respostas claras a duas questões: o que é consciência e como ela se forma. Conforme Leontiev (1978), a consciência é um atributo do psiquismo complexo culturalmente formado, isto é, que se institui pela inserção do sujeito na cultura e consequentemente, pela via da apropriação da linguagem.

Nessa direção, em anuência ao autor supramencionado, a consciência é uma forma de reflexo daquilo que existe fora dela, reflexo este a quem cumpre orientar o sujeito na realidade concreta. Sua gênese reside na conquista da distinção entre sujeito e objeto, quando o sujeito se distingue daquilo que o rodeia, tornado, então, 'objeto de sua consciência'. Nisso reside a possibilidade de que o indivíduo analise não só o objeto tornado outro mas, igualmente, se coloque como alvo de sua própria análise.

Ademais, a consciência não é um 'mundo interior' que se defronta com o 'mundo exterior', mas desponta como qualidade da imagem subjetiva que a pessoa constrói acerca da realidade objetiva. Por conseguinte, a análise da formação da consciência demanda que se leve em conta que toda imagem - não sendo o objeto, mas seu reflexo -, comporta distorções. Haja vista que a consciência se institui por ação social e comporta distorções, há que se levar em conta as condições que as favorecem. Dentre tais condições destacamos: limites na captação do objeto pelo sujeito; significados parciais e/ou equivocados atribuídos socialmente aos objetos e apropriados pelo sujeito e, acima de tudo, distorções resultantes do interesse da classe dominante de fazer de suas ideias as ideias dominantes e, com isso, converter sua pseudoverdade em uma verdade ingenuamente crível.

Destaque-se, pois, que a consciência não é 'substantivo', mas 'adjetivo', portanto, uma qualidade que, como tal, comporta distorções. Tais fatos conduzem à constatação de que o percurso intencional de formação da consciência não possa ser outro, senão, seu enriquecimento qualitativo que, a nosso juízo, significa torná-la maximamente fidedigna àquilo que reflete, haja vista ser este o caminho pelo qual as distorções podem ser dirimidas. É com este intuito que afirmamos como tarefa nuclear da educação escolar a disponibilização, aos indivíduos, dos produtos do trabalho de decodificação abstrata (teórica) acerca da realidade concreta que a humanidade já empreendeu e continua a 
empreender, tendo em vista captar a realidade concreta para além das aparências superficiais, fenomênicas.

O produto deste trabalho, por seu turno, encontra-se objetivado no acervo científico, artístico e filosófico historicamente sistematizado e referendado pela prática social do conjunto dos homens, tal como propalado por Saviani (2011). Por conseguinte, há que se destacar que as formas, os procedimentos e expedientes que se voltam à captação do real aparente - centrados em conhecimentos ou conceitos de senso comum e disponibilizados inclusive pelas vivências cotidianas -, não se aplicam aos conteúdos aptos a tornar o real inteligível, corroborando a fidedignidade da consciência. Portanto, para que a educação escolar opere a serviço da humanização e contra a alienação há que se afirmá-la pela qualidade dos conhecimentos que veicula e pela defesa do ato de ensinar. Assim concebida, ela não se identifica com o ensino de 'quaisquer conteúdos' a ocorrer num edifício denominado escola.

\section{REFERÊNCIAS}

ANTUNES, R.; POCHMANN, M. A desconstrução do trabalho e a explosão do desemprego estrutural e da pobreza no Brasil. In: CIMADAMORE, A. D.; CATTANI, A. D. (Org). Produção de pobreza e desigualdade na América Latina. Porto Alegre: Tomo Editorial/Clacso, 2007, p. 195-209.

CARVALHO, S. R. Políticas neoliberais e educação pós-moderna no ensino paulista. Dissertação de Mestrado. Universidade Estadual Paulista, Faculdade de Ciências e Letras. Araraquara, 2010.

GADOTTI, M. História das ideias pedagógicas. São Paulo: Ática, 2002.

LEONTIEV, A. N. O desenvolvimento do Psiquismo. Lisboa, Livros Horizonte, 1978.

LIMA, M. E. A. Sociedade do futuro e novas relações de trabalho: a crise do emprego e o emprego na crise. Cadernos de Psicologia, Belo Horizonte, UFMG. v. 7, n. 1, p. 17-27, 1998.

MARTINS, L. M. O desenvolvimento do psiquismo e a educação escolar: contribuições à luz da psicologia histórico-cultural e da pedagogia histórico-crítica. Campinas-SP: Autores Associados, 2013.

MARX, K. Manuscritos econômico-filosóficos. São Paulo: Boitempo, 2010.

PEREIRA, M. F. R. Dois sentidos para a educação na década de 1980: democracia e cidadania/ implicações históricas. In: LOMBARDI, J. C.; SAVIANI, D. NASCIMENTO, M. I. M. (Org.). Navegando pela história da educação brasileira. Campinas: Graf. FE: 
HISTEDBR, 2006. p. 1-29. Disponível em:

<http://www.histedbr.fae.unicamp.br/navegando/artigos_frames/artigo_071.html>. Acesso em: 14 nov. 2008.

SALA, M. Socialização do conhecimento ou sociabilidade adaptativa: trabalho e educação diante das transformações do capitalismo contemporâneo. Dissertação de Mestrado. Universidade Estadual Paulista. Faculdade de Ciências e Letras. Araraquara, 2009.

SAVIANI, D. Educação: do senso comum à consciência filosófica. 17 ed. Campinas-SP: Autores Associados, 2007a.

SAVIANI, D. Trabalho e educação: fundamentos ontológicos e históricos. Revista Brasileira de Educação, v. 12, n. 34, jan./abr., p. 152-180, 2007 b.

SAVIANI, D. A Pedagogia no Brasil: história e teoria. Campinas: Autores Associados, 2008a.

SAVIANI, D. Escola e Democracia. Campinas-SP: Autores Associados, edição comemorativa, 2008b.

SAVIANI, D. História das ideias pedagógicas no Brasil. 3 ed. Campinas-SP: Autores Associados, 2010.

SAVIANI, D. Pedagogia histórico-crítica: primeiras aproximações. 11 ed. Campinas-SP: Autores Associados, 2011.

SAVIANI, D. O lunar de Sepé: paixão, dilemas e perspectivas na educação. CampinasSP: Autores Associados, 2014.

\section{Como referenciar este artigo}

MARSIGLIA, Ana Carolina Galvão.; MARTINS, Lígia Márcia. A natureza contraditória da educação escolar: tensão histórica entre humanização e alienação. Revista IberoAmericana de Estudos em Educação, Araraquara, v. 13, n. 4, p. 1697-1710, out./dez., 2018. E-ISSN: 1982-5587. DOI: 10.21723/riaee.unesp.v13.n4.out/dez.2018.10265

Submetido em: 20/08/2017

Aprovado em: 16/05/2018 